\title{
Electro-Characterization of Polypyrolle Electrosynthesized on a Montmorillonite Host-Matrix, In Aqueous Media Containing Sulphuric Acid as Supporting Electrolyte.
}

\author{
Duke Orata ${ }^{*}$, Marina Mukabi, HellenNjenga, Amir Yusuf, \\ Department of ChemistryUniversity of NairobiP.O. Box 30197-00100Nairobi, Kenya.
}

\begin{abstract}
In this paper polypyrolle has been electrosynthesised from an aqueous media containing the pyrolle monomer and sulphuric acid as the supporting electrolyte.

The redox properties of polypyrolle on carbon graphite working electrode and on a clay montmorillonite host matrix has also been reported.

The results obtained from plots of oxidative and reductive peak currents yield redox efficiencies above $95 \%$ for the polypyrolle redox process.

The polypyrolle redox process is also shown to be diffusion limited.

The reduction in the rate of electrodeposition of polypyrolle on a polyaniline loaded clay montmorillinite hostmatrix, is a veiled confirmation of intercalation of the polyaniline in montmorillonite matrix.

KeyWords:Polypyrolle, Polyaniline, Electrosynthesised, Clay Montmorillonite (bentonite), Cyclicvoltammogram, Host matrix
\end{abstract}

\section{Introduction}

Polymers have traditionally been considered exclusively as insulators, a property which has allowed their use in the fabrication of various electrical gadgets.

During the 1970s, a new class of polymers refered to as electronically conducting polymers, possessing high electronic conductivity in the partially oxidized state was reported by several researchers.

The emergence of these electronically conducting polymers resulted in a paradigmatic change in scientific thinking opening up new vistas/frontiers in chemistry, physics and materials science.

Polyacetylene the pioneer conducting polymer was prepared by Shirakawa and coworkers, while its 'doping 'by the group led by MacDiarmid and Heeger led to improved levels of conductivity. These splendid researches on electronically conducting polymers are found references (1-10) and references therein.

Electronically conducting polymers- polyaniline, polythiophene, and polypyrrole have been the subject of intense research and this has been as a result of their unique properties such as low density, high anisotropy of electrical conduction, versatility in methods of production and non-metallic temperature dependence of conductivity.

Electrochemical and chemical methods have been used to synthesize these polymers. Electrochemical techniques enable controlled synthesis of these compounds in addition to allowing qualitative and quantitative assessment of their redox states.

Conducting polymers tend to be brittle, infusible, and intractable. The presence of conjugated double bonds and and at times cross linked covalent bonds, result in strong inter- and intra-molecular interactions.

The application of these polymers in various fields require that, they be stable and easy to process, properties which are strongly dependent on on the processing conditions such as temperature, concentration, and stoichiometry as well as on the type of monomer, oxidant, dopant, and solvent used (1-10).

Electronically conducting polymers find application in the fields of energy storage, electrocatalysis, organic electrochemistry, bioelectrochemistry, photoelectrochemistry, electroanalysis, sensors, electrochromic displays, microsystem technologies, electronic devices, microwave screening and corrosion protection, etc (see references 11-13 and references therein).

In this paper the electrosynthesis and the redox features of polypyrolle electrogenerated from an aqueous media containing sulphuric acid as supporting electrolyte is reported. The working electrodes are bare carbon graphite and clay montmorillonite as a host matrix on carbon graphite electrode. Polypyrolle redox features on a polyaniline loaded montmorillonite host matrix is also reported. 


\section{Experimental Section:}

Analytical grade acids were used as received without further purification. The pyrolle and aniline monomers were triply distilled until a colorless liquid was obtained. They liquids were purged using inert gas and stored under nitrogen.

The de-ionised water used was from a Millipore-purification system and occasionally triply distilled water was used.

The cyclic voltammograms were generate from a potentiostat/galvanostat used in conjugation with a universal programmer which generated the cyclical potential waves. The signals were then fed into an $x-y$ recorder.

The modification of the carbon graphite working electrode was achieved by cycling the potential of the working electrode within a given potential window in an electrolyte solution containing pyrolle or aniline monomers. The clay montmorillonite modification of the carbon graphite working electrode surface was achieved as discussed by Orata and Segor (14-15).

\section{Results And Discussion:}

Polypyrolle was electrodeposited from an electrolyte media containing $0.05 \mathrm{M}$ pyrolle and $1 \mathrm{M} \mathrm{H}_{2} \mathrm{SO}_{4}$ The potential of the carbon graphite working electrode was cycled from $-0.2 \mathrm{~V}$ to $0.85 \mathrm{~V}$ at a scan rate of $20 \mathrm{mV} / \mathrm{sec}$. The resultant CV is shown in Figure 1. The oxidation peak potential occurred at $0.53 \mathrm{~V}$ and the reduction potential at $0.316 \mathrm{~V}$.

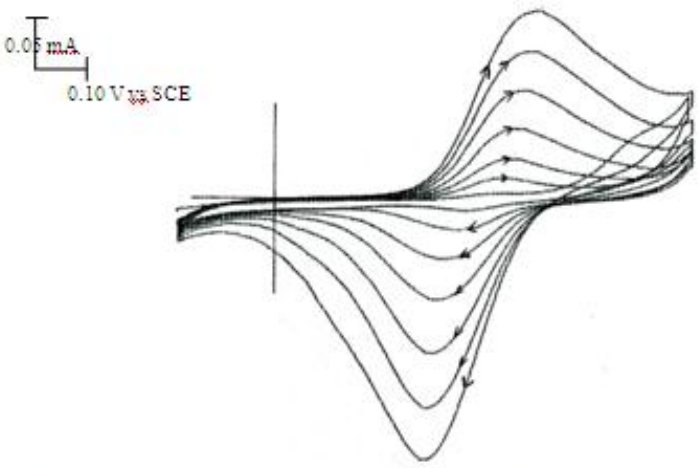

Figure 1: CV response of the electrodeposition of polypyrolle on a bare carbon working electrode in an electrolyte solution containing $0.05 \mathrm{M}$ pyrolle and $1 \mathrm{M} \mathrm{H}_{2} \mathrm{SO}_{4}$. Potential range was from $-0.2 \mathrm{~V}$ to $0.85 \mathrm{~V}$. Scan rate $20 \mathrm{mV} / \mathrm{sec}$.

It is observed that the polypyrolle redox process is quasi-reversible i.e., the oxidation potential does not correspond to the reduction potential.

When the positive potential limit was varied, it was observed that, the rate of electrodeposition of polypyrolle appears in general to increase with the positive potential limit. See Figure 2.

It is important to note that, for the potential limit $-0.2 \mathrm{~V}$ to $0.95 \mathrm{~V}$, the electrodeposition rate decreases. We propose that, as the positive potential limit is increased, the rate of electro-degradation is much higher than the electrodeposition rate, hence the reduction in the electrodeposition rate. 


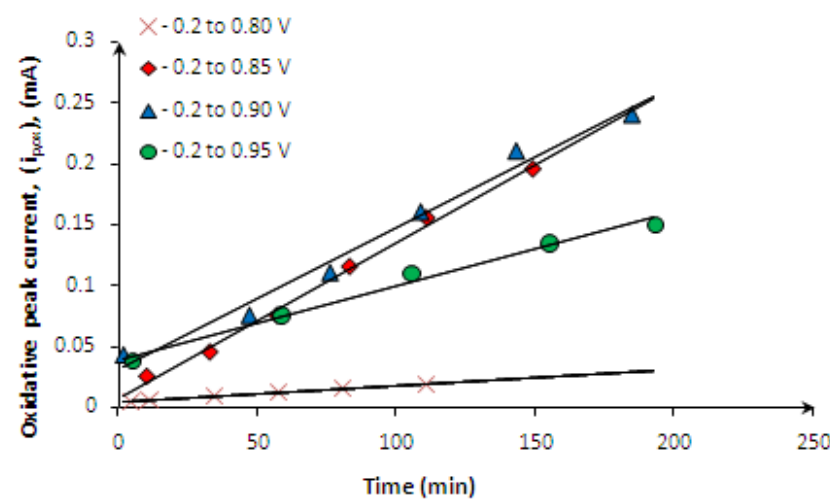

Figure 2: Plot of oxidative peak current, $\left(i_{p, 0 v}\right),(\mathrm{mA})$ versus time $(\mathrm{min})$ for polypyrolle electrodeposited on a bare carbon electrode in solution containing $0.05 \mathrm{M}$ pyrolle and $1 \mathrm{M} \mathrm{H}_{2} \mathrm{SO}_{4}$ at different potential ranges -0.2 to $0.80 \mathrm{~V}, 0.85 \mathrm{~V}, 0.90 \mathrm{~V}, 0.95 \mathrm{~V}$, scan rate $20 \mathrm{mV} / \mathrm{s}$.

When the oxidative peak current was plotted versus the reductive peak current, we obtain a linear plot and a redox efficiency of $99 \%$, suggesting that for every incremental increase in the oxidative peak current there is a corresponding increase in the reductive peak current. See Figure 3.

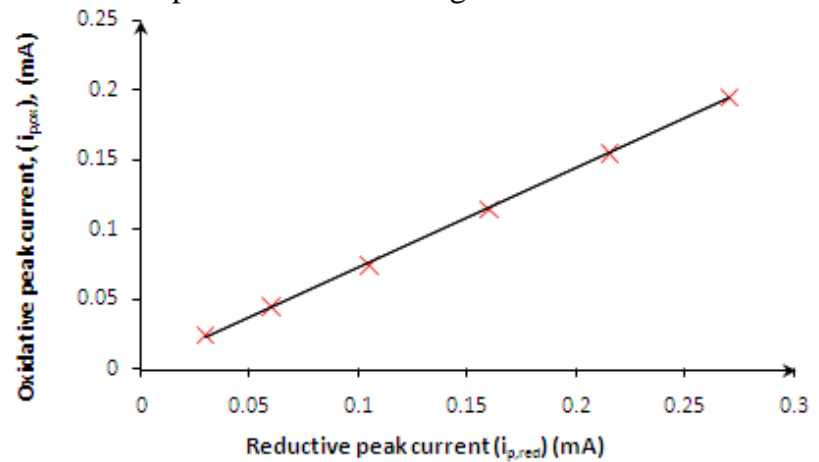

Figure 3: Plot of oxidative peak current versus reductive peak current for polypyrolle electrodeposited on a bare carbon electrode in solution containing $0.05 \mathrm{M}$ pyrolle and $1 \mathrm{M} \mathrm{H}_{2} \mathrm{SO}_{4}$ at a potential range -0.2 to 0.85 $\mathrm{V}$, scan rate $20 \mathrm{mV} / \mathrm{s}$.

When the rate of change of oxidative charge is computed for the different potential ranges, once again we observe that it increases generally, except for the $0.80 \mathrm{~V}$ and $0.95 \mathrm{~V}$ potential limit. Unlike in the case of the $0.95 \mathrm{~V}$ potential limit where we propose that, the electro-degradation process is predominant, it is important to mention that, for the potential limit $-0.2 \mathrm{~V}$ to $0.80 \mathrm{~V}$ non-variation of the oxidative charge with time is probably as a result of the low concentration of pyrolle radical cations electro-generated, hence the coupling process leading to the formation of the polymer is reduced. See Figure 4.

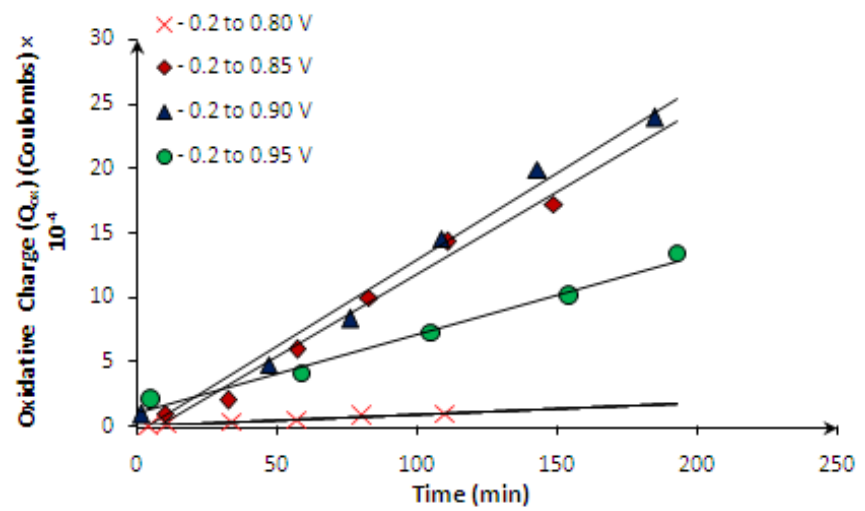

Figure 4: Plot of oxidative charge, $Q_{o x}$ (Coulombs) versus time ( $\mathrm{min}$ ) for polypyrolle electrodeposited on a bare carbon electrode in solution containing $0.05 \mathrm{M}$ pyrolle and $1 \mathrm{M} \mathrm{H}_{2} \mathrm{SO}_{4}$ at potential ranges -0.2 to 0.80 $\mathrm{V}, 0.85 \mathrm{~V}, 0.90 \mathrm{~V}$ and $0.95 \mathrm{~V}$, scan rate $20 \mathrm{mV} / \mathrm{s}$.

When the oxidative peak currents are plotted as a function of the scan rate and square root of scan rate, we obtain a linear plot in the case of the latter. This suggests that, the polypyrolle redox process is diffusion limited. See Figures 5 and 6. 


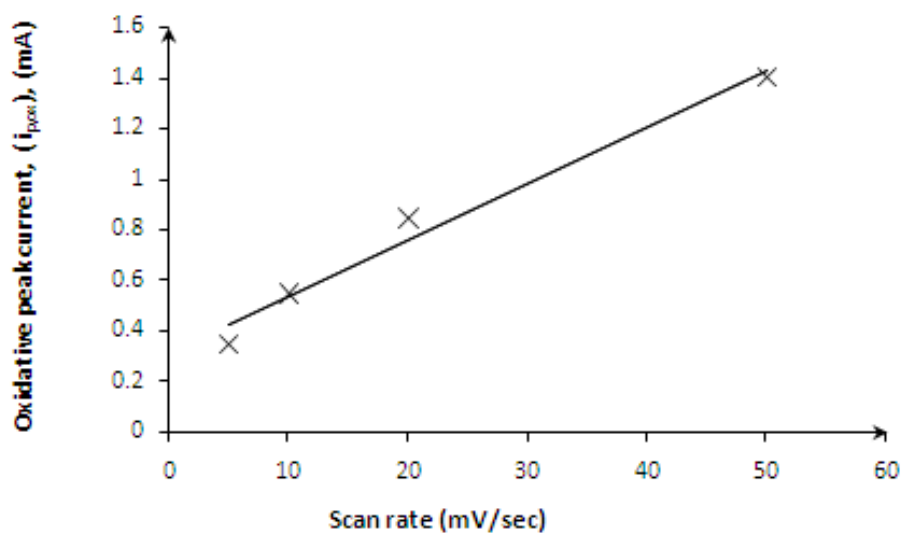

Figure 5: A plot of oxidative peak current (ip, ox) versus scan ratefor electrodeposition of polypyrolle in solution containing $0.05 \mathrm{M}$ pyrolle and $1 \mathrm{M} \mathrm{H}_{2} \mathrm{SO}_{4}$. Potential range -0.2 to $0.80 \mathrm{~V}$.

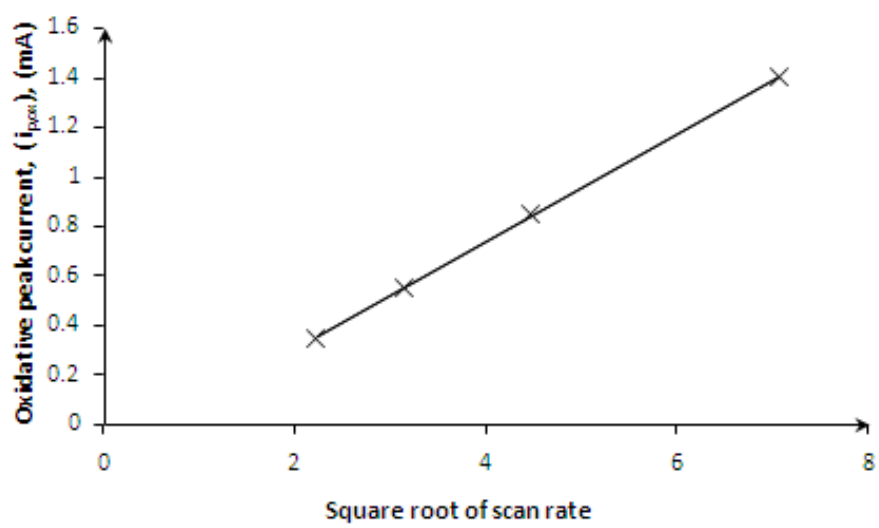

Figure 6: A plot of oxidative peak current $\left(i_{\text {por }}\right)$ versus square root of scan ratefor electrodeposition of polypyrolle in solution containing $0.05 \mathrm{M}_{\text {pyrolle and }} 1 \mathrm{M} \mathrm{H}_{2} \mathrm{SO}_{4}$. Potential range -0.2 to $0.80 \mathrm{~V}$.

PH dependence studies were conducted where the polypyrolle was transferred into electrolyte media containing different concentrations of sulphuric acid but no pyrolle monomer. The results indicate that the polypyrolle oxidative potential is not linearly dependent on the electrolyte $\mathrm{pH}$.

This non-linear variation of oxidative potential versus solution $\mathrm{pH}$, probably suggests that the number of protons and electrons in the polypyrolle redox process varies and is probably dependent on the morphology of the film. See Figure 7.

The non-linearity can also be attributed further to the fact that, for the potential window from $-0.2 \mathrm{~V}$ to $0.8 \mathrm{~V}$, there is significantly low concentration of pyrolle radical cations formed, hence the coupling process leading to polymer formation significantly reduced.

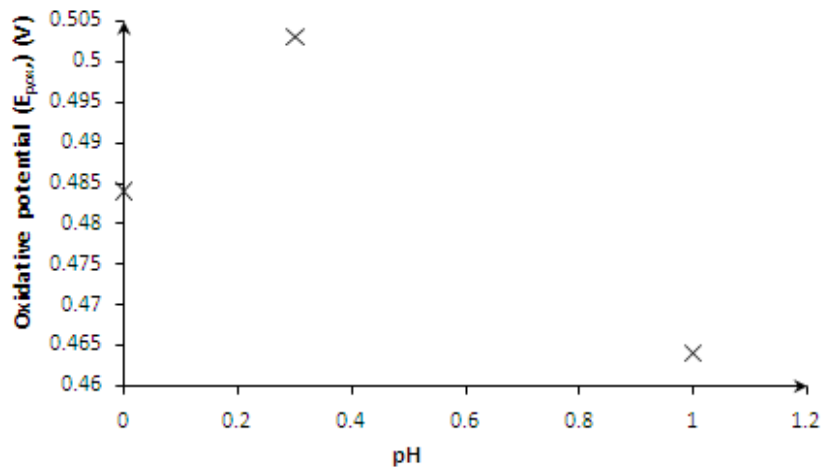

Figure 5.7. Plot of oxidative peak potential, $\left(\mathrm{E}_{\mathrm{p}, \mathrm{ox}}\right),(\mathrm{V})$ versus $\mathrm{pH}$ of $\mathrm{H}_{2} \mathrm{SO}_{4}$ electrolyte solution in the absence of pyrolle monomer. The potential range was -0.2 to $0.80 \mathrm{~V}$, scan rate $20 \mathrm{mV} / \mathrm{s}$. 


\section{Simultaneous Electro-deposition of Polyaniline and Polypyrolle:}

In this study attempts were made to electrodeposit polyaniline and polypyrolle simultaneously from an electrolyte media containing equal amounts of aniline and pyrolle monomers $(0.05 \mathrm{M}$ each). The potential of the working electrode was cycled from $-0.2 \mathrm{~V}$ to $0.80 \mathrm{~V}$ at a scan rate of $20 \mathrm{mV} / \mathrm{sec}$. The choice of the potential limit as $0.80 \mathrm{~V}$ despite the empirical observation that, the concentration of pyrolle radical cations is significantly reduced hence the coupling of the pyrolle radical cations statistically reduced, was dictated by the fact that, at higher potentials the polyaniline polymer electro-degrades forming quinine/imine derivatives.

The cyclic voltammetric response obtained, revealed an oxidation peak at $0.05 \mathrm{~V}$ corresponding to the polyaniline oxidation peak. This oxidation peak does not have a distinct reduction peak. There is a broad oxidation peak at approximately 0.3 Vand a broad reduction peak at approximately $0.15 \mathrm{~V}$. We observe that the reductive peak potential shifts negatively with continued cycling, probably an indicator that this peak is not exclusively due to polypyrolle redox process, but rather a composite with redox characteristics of polyaniline. See Figure 8.

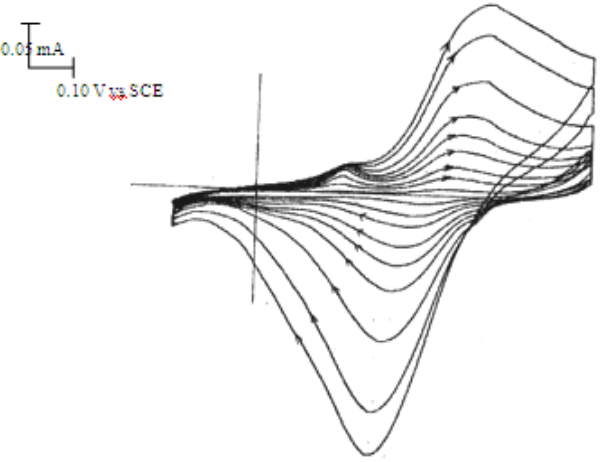

Figure 8: $\mathrm{CV}$ response of simultaneous electrodeposition of polyaniline and polypyrolle on a bare carbon
electrode in solution containing $0.05 \mathrm{M}$ aniline, $0.05 \mathrm{M}$ pyrolle and $1 \mathrm{M} \mathrm{H}_{2} \mathrm{SO}_{4}$. Potential range -0.2 to 0.80 $\mathrm{V}$, scan rate $20 \mathrm{mV} / \mathrm{s}$

A plot of the oxidative peak current versus time for the polyaniline and polypyrolle (See Figure 9) indicate that the rate of electrodeposition of polyaniline is much less than that for polypyrolle. Since in the absence of polypyrolle, polyaniline is known to exhibit high electrodeposition rates within this potential window, its reduced activity probably is a pointer to unfavorable interaction between the two redox centres i.e., an increase in the polymerization Gibbs free energy $\left(\Delta \mathrm{G}_{\mathrm{pan}}\right)$ for polyaniline..

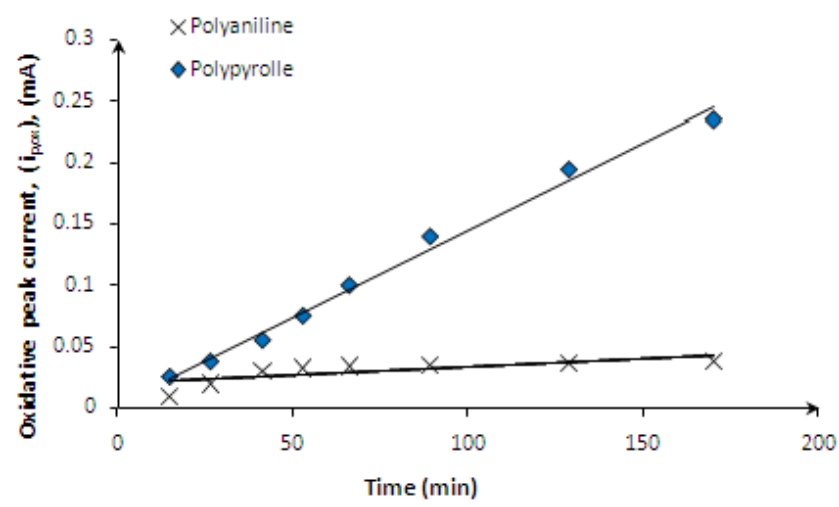

Figure 9: Plot of oxidative peak currents of polyaniline and polypyrolle, $\left(i_{p, 0 x}\right),(\mathrm{mA})$ versus time $(\mathrm{min})$ for simultaneous electrodeposition of polyaniline and polypyrolle on a bare carbon electrode in solution containing $0.05 \mathrm{M}$ aniline, $0.05 \mathrm{M}$ pyrolle and $1 \mathrm{M} \mathrm{H}_{2} \mathrm{SO}_{4}$. Potential range -0.2 to $0.80 \mathrm{~V}$, scan rate $20 \mathrm{mV} / \mathrm{s}$.

A plot of the oxidative and reductive peak currents (see Figure 10), for the polypyrolle redox process, once again points to a highly efficient process with the redox efficiency above $95 \%$. 


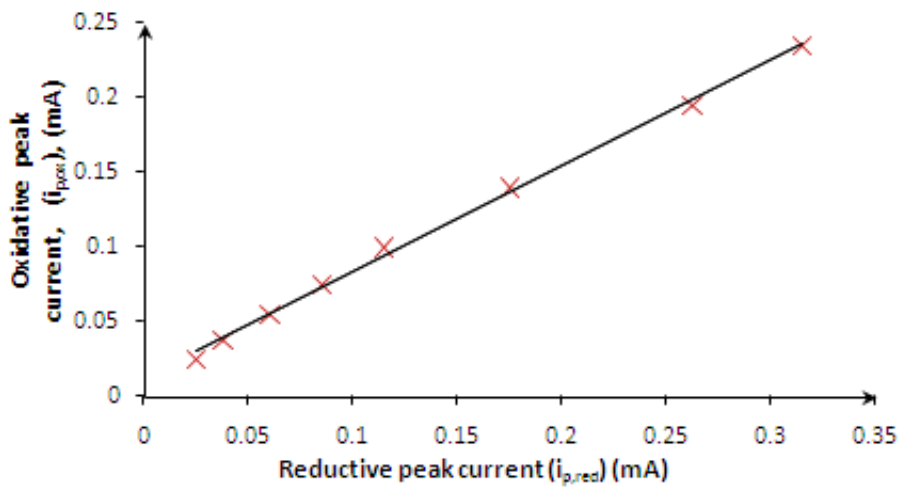

Figure 10: Plot of oxidative peak current (ip, ox), $(\mathrm{mA})$ versus reductive peak current (ip, red), $(\mathrm{mA})$ for polypyrolle. Potential range -0.2 to $0.80 \mathrm{~V}$, scan rate $20 \mathrm{mV} / \mathrm{s}$.

Scan rate dependence studies conducted on the polyaniline and polypyrolle redox process, yielded a linear plot for polyaniline and a non-linear plot for the polypyrolle redox process, when the oxidative peak currents were plotted as a function of scan rate. This points to the fact that, polyaniline is a surface attached species, while polypyrolle redox process is diffusion limited

See Figure 11.

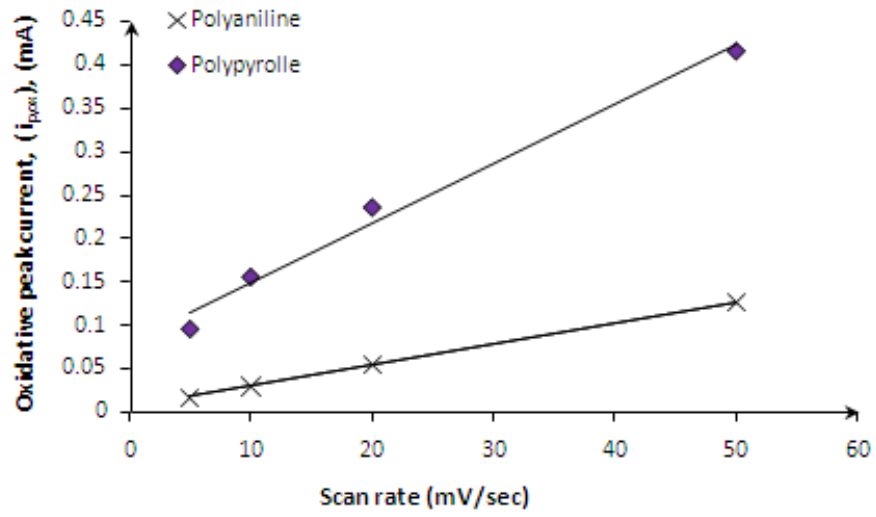

Figure 11: Plot of oxidative peak currents of polyaniline and polypyrolle, $\left(i_{p, 0 x}\right),(\mathrm{mA})$ versus scan rate for simultaneous electrodeposition of polyaniline and polypyrolle on a bare carbon electrode in solution containing $0.05 \mathrm{M}$ aniline, $0.05 \mathrm{M}$ pyrolle and $1 \mathrm{M} \mathrm{H}_{2} \mathrm{SO}_{4}$. Potential range -0.2 to $0.80 \mathrm{~V}$.

It was further observed that, when the oxidative peak currents for polyaniline and polypyrolle when plotted as a function of square root of scan rate (see Figure 12), both redox processes yielded linear plots. This unexpected behavior of polyaniline is probably a pointer to the fact that the film is actually a composite of polyaniline and polypyrolle.

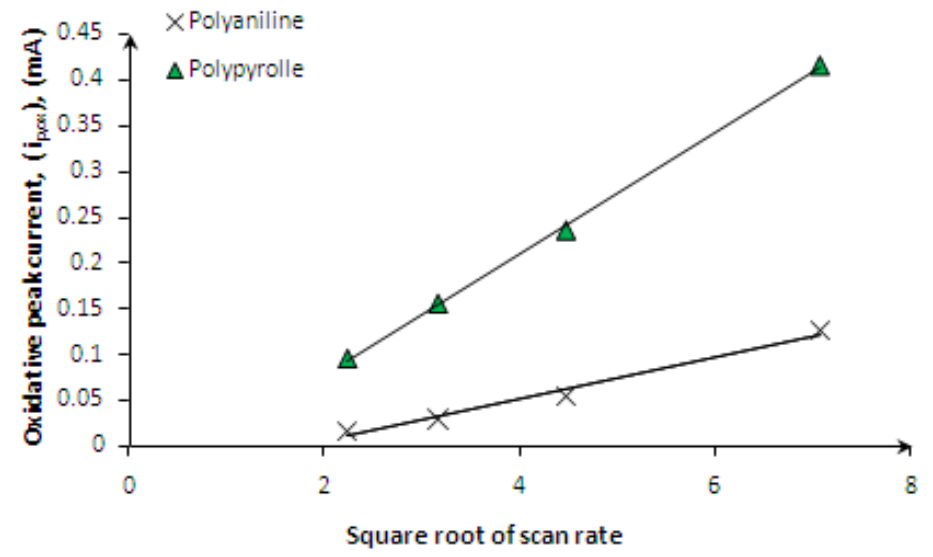

Figure 12: Plot of oxidative peak currents of polyaniline and polypyrolle, $\left(\mathrm{i}_{\mathrm{p}, 0 \mathrm{v}}\right),(\mathrm{mA})$ versus square root of scan rate for simultaneous electrodeposition of polyaniline and polypyrolle on a bare carbon electrode in solution containing $0.05 \mathrm{M}$ aniline, $0.05 \mathrm{M}$ pyrolle and $1 \mathrm{M} \mathrm{H}_{2} \mathrm{SO}_{4}$. Potential range -0.2 to $0.80 \mathrm{~V}$. 


\section{First Scan Response of Pyrolle:}

A fresh polypyrolle film was electrodeposited from an electrolyte solution containing pyrolle monomer and sulphuric acid as earlier discussed. When the polypyrolle wastransferred to a solution containing0.5 M,1 M, $1.5 \mathrm{M}$ and $2 \mathrm{M} \mathrm{H}_{2} \mathrm{SO}_{4}$, and the first scan response on cycling the potential from $-0.2 \mathrm{~V}$ to $0.8 \mathrm{~V}$ and back to $-0.2 \mathrm{~V}$ recorded, we observe a scafolding of the cyclic voltammogram typical of nucleation in metals. See Figure 13.

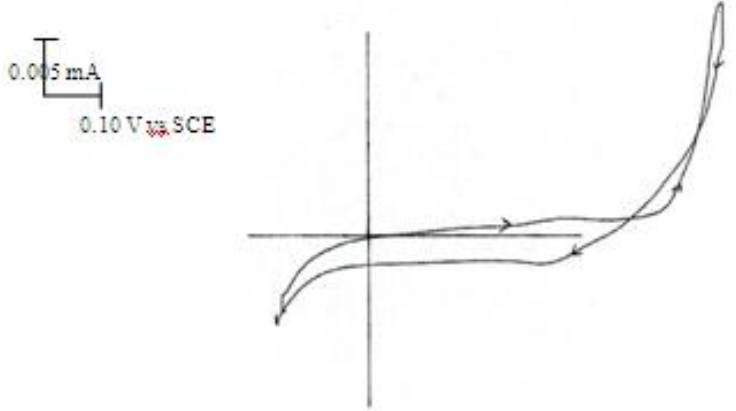

Figure 13: First scan response of polypyrollein $1.0 \mathrm{M} \mathrm{H}_{2} \mathrm{SO}_{4}$. Potential range -0.2 to $0.80 \mathrm{~V}$, scan rate 20 $\mathrm{mV} / \mathrm{s}$.

\section{Electrodeposition of Polypyrolle on Bentonite Modified Electrode:}

In Figure 14, we observe the CV response obtained on electrodeposition of polypyrolle on a bentonite modified electrode in solution containing $0.2 \mathrm{M}$ pyrolle and $1.5 \mathrm{M} \mathrm{H}_{2} \mathrm{SO}_{4}$. The potential was cycled from -0.3 to $0.85 \mathrm{~V}$ at a scan rate of $20 \mathrm{mV} / \mathrm{s}$.

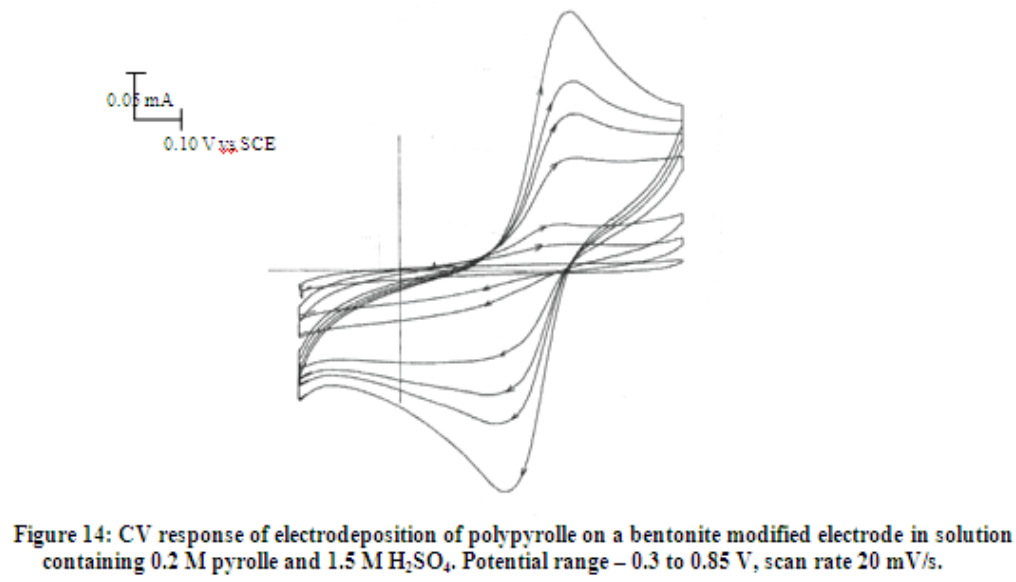

We observe that the differences between the oxidative and reductive peak potentials decreases with time. The variations in the potentials/times are: $250 \mathrm{mV} / 62 \mathrm{mins} ; 230 \mathrm{mV} / 76 \mathrm{mins} ; 210 \mathrm{mV} / 84 \mathrm{mins}$ and $180 \mathrm{mV} / 105 \mathrm{mins}$. These decrease in the potential differences suggest that as more film is deposited the redox process approaches quasi-reversibility. It is possible that the polypyrolle undergoes autocatalysis as more film is electrodeposited, hence affecting the redox potentials. Autocatalysis has been observed in other conducting polymers such as polyaniline.

The rate of electrodeposition of polypyrolle on the bentonite host matrix was computed. A plot of the oxidative peak current versus time is shown in Figure 15. We observe that, polypyrolle film deposited increases with time, given that the oxidative peak current is proportional to the amount of film/or surface coverage .

The deposition is not completely linear. This is expected given that, the rate of deposition of the film depends also on the morphology of the film as was shown from ellipsometric studies and quartz crystal microbalance studies (QCM). 


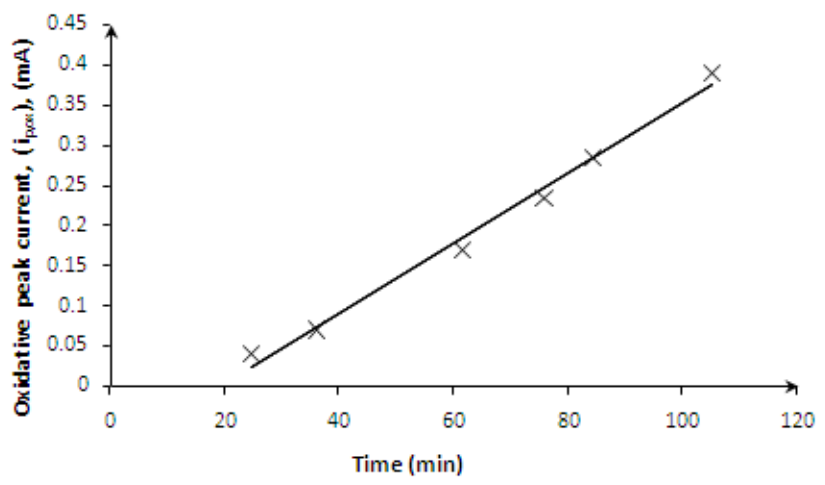

Figurel5: Plot of oxidative peak currents, (ip, ox), $(\mathrm{mA})$ versus time $(\mathrm{min})$ for polypyrolle electrodeposited on bentonite modified electrode in solution containing $0.2 \mathrm{M}$ pyrolle and $1.5 \mathrm{M} \mathrm{H}_{2} \mathrm{SO}_{4}$. Potential range -0.3 to $0.85 \mathrm{~V}$, scan rate $20 \mathrm{mV} / \mathrm{s}$.

The polypyrolle electrodeposition process on bentonite host-matrix is quite efficient, as can be observed from the plot of anodic versus cathodic peak currents. We observe that for every incremental increase in the anodic peak current there is a corresponding increase in the cathodic peak current. See Figure 16.

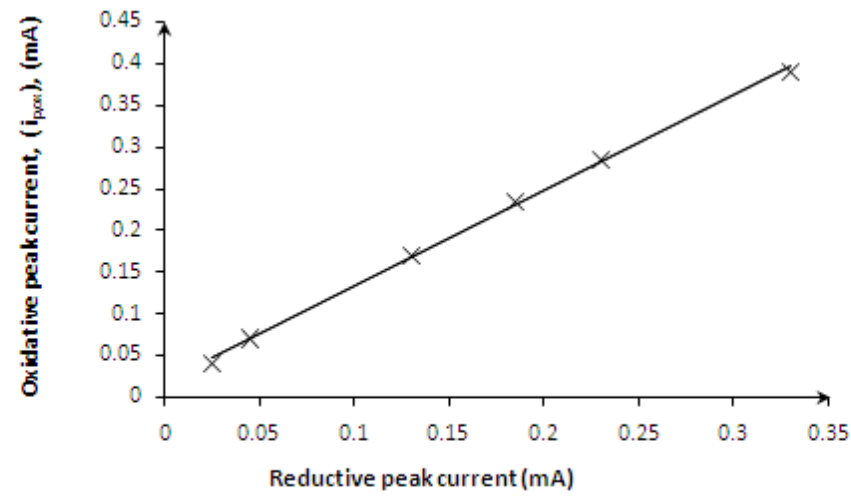

Figure 16: Plot of oxidative peak current, (ip, and ox), (mA) versus reductive peak current (ip, red), (mA) for polypyrolle electrodeposited on bentonite modified electrode in solution containing $0.2 \mathrm{M}$ pyrolle and $1.5 \mathrm{M}$ $\mathrm{H}_{2} \mathrm{SO}_{4}$. Potential range -0.3 to $0.85 \mathrm{~V}$, scan rate $20 \mathrm{mV} / \mathrm{s}$.

$\mathrm{pH}$ dependence studies on polypyrolle does not yield significant information, which can facilitate the computation of the number of electrons and protons involved in the redox process. The variation of the oxidative peak potential and $\mathrm{pH}$ is quite haphazard, suggesting a non-linear dependence of the polypyrolle redox process on electrolyte solution $\mathrm{pH}$. See Figure 17.

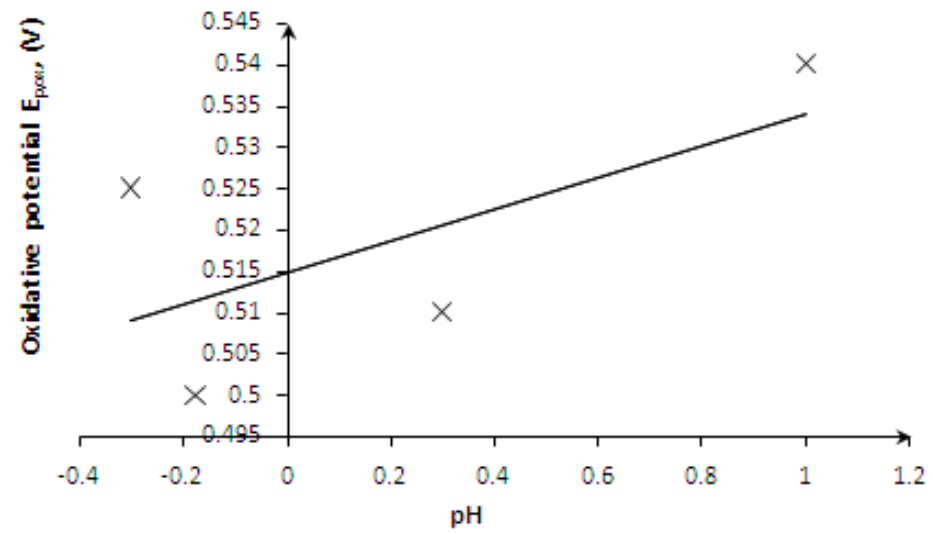

Figure 17: Plot of oxidative potential, $\left(\mathrm{E}_{\mathrm{p}, \mathrm{sod}} \mathrm{ov}\right)$, (V) versus $\mathrm{pH}$ of $\mathrm{H}_{2} \mathrm{SO}_{4}$ solution for polypyrolle electrodeposited on bentonite modified electrode in solution containing $0.2 \mathrm{M}$ pyrolle and $1.0 \mathrm{M} \mathrm{H}_{2} \mathrm{SO}_{4}$. Potential range -0.3 to $0.85 \mathrm{~V}$, scan rate $10 \mathrm{mV} / \mathrm{s}$.

In the next set of experiments the variation of the oxidative charge versus time for the polypyrolle redox process was computed (see Figure 18). From the plot obtained it is apparent that, initially the electrodeposition process is slow but as more polymer is electrodeposited, the electro-deposition rate increases. This is probably the result of autocatalysis which results in a significant change in the rate of change of the 
oxidative peak current. We further propose that, morphology of the film also affects the rate of electrodeposition.

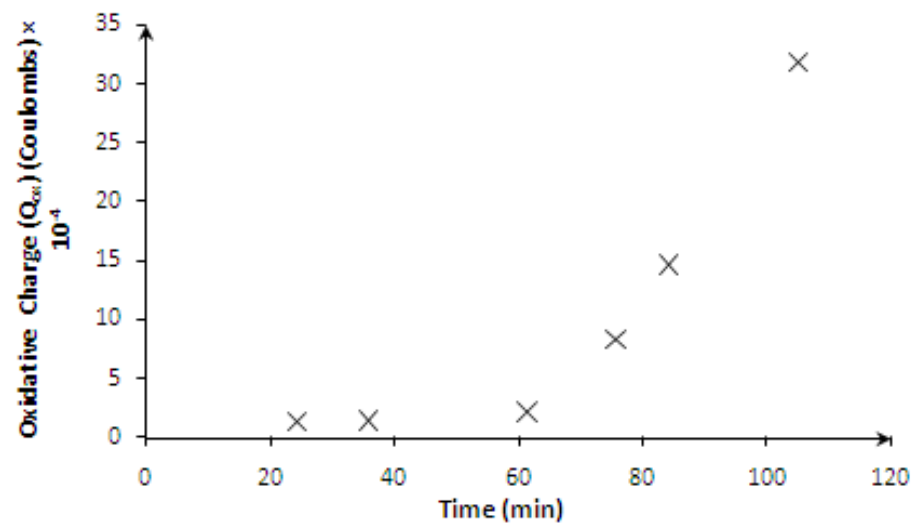

Figure 18: Plot of oxidative charge, $\left(Q_{\text {ox }}\right)$, (Coulombs) versus time for polypyrolle electrodeposited on bentonite modified electrode in solution containing $0.2 \mathrm{M}$ pyrolle and $1.5 \mathrm{M} \mathrm{H}_{2} \mathrm{SO}_{4}$. Potential range -0.3 to $0.85 \mathrm{~V}$, scan rate $20 \mathrm{mV} / \mathrm{s}$.

We also observe that the oxidative peak potential of the polypyrolle film does not change significantly with time. This suggests that, the redox centres in polypyrolle do not interact with the redox centres of the isomorphically substitutable metal ions in the octahedral $\left(\mathrm{O}_{\mathrm{h}}\right)$ layer of a clay montmorillonite matrix (see Figure 19)

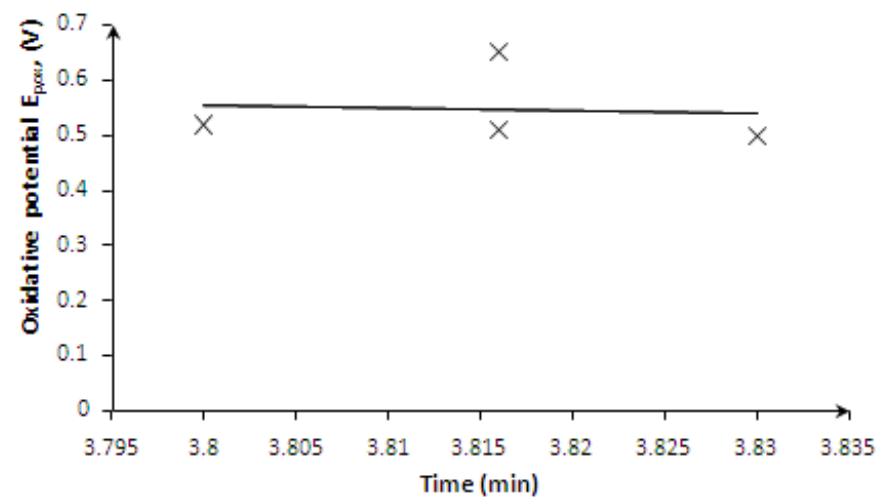

Figure 19: Plot of oxidative potential, $\left(\mathrm{E}_{\mathrm{p}, 2 \mathrm{~s}}\right),(\mathrm{V})$ versus time $(\mathrm{min})$ for polypyrolle electrodeposited on bentonite modified electrode in solution containing $0.2 \mathrm{M}$ pyrolle and $0.1 \mathrm{M} \mathrm{H}_{2} \mathrm{SO}_{4}$. Potential range -0.3 to $0.85 \mathrm{~V}$, scan rate $10 \mathrm{mV} / \mathrm{s}$.

Electrodeposition of Polypyrolle on a Bentonite-Polyaniline Modified Electrode

A bentonite -polyaniline modified working electrode was developed by cycling the potential of a bentonite modified electrode in a solution containing $0.1 \mathrm{M}$ aniline and $1 \mathrm{M} \mathrm{H}_{2} \mathrm{SO}_{4}$ from $-0.2 \mathrm{~V}$ to $0.85 \mathrm{~V}$ at a scan rate of $20 \mathrm{mV} / \mathrm{sec}$. The cyclic voltammetric response obtained on electrodeposition of polypyrolle on the bentonite-aniline modified electrode, in solution containing $0.2 \mathrm{M}$ pyrolle and $1.5 \mathrm{M} \mathrm{H}_{2} \mathrm{SO}_{4}$, is shown in Figure 20. The potential of bentonite - polyaniline modified electrode was cycled from -0.3 to $0.85 \mathrm{~V}$ at a scan rate of $20 \mathrm{mV} / \mathrm{s}$. See Figure 20. 


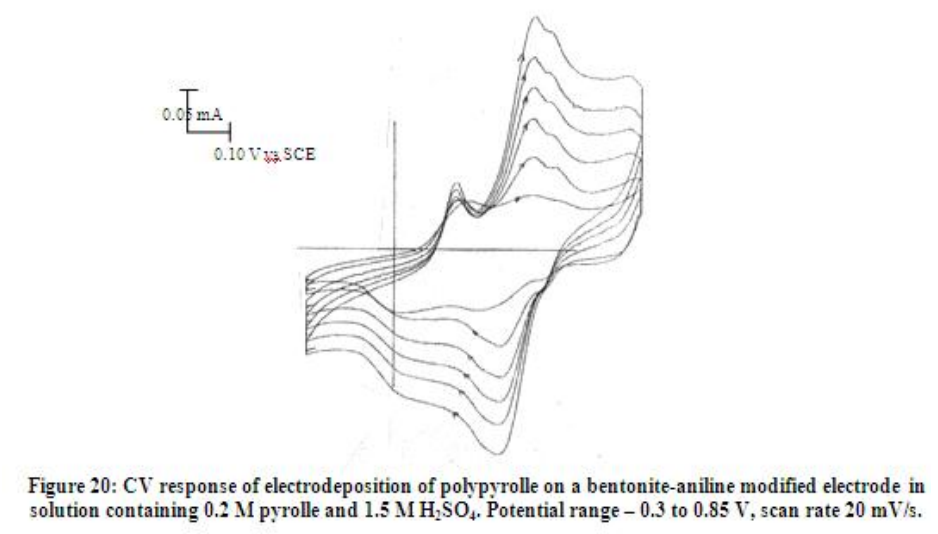

We observe several oxidative peak potentials. The oxidative peak potential for polyaniline occurs at $0.22 \mathrm{~V}$ and for polypyrolle is at $0.49 \mathrm{~V}$. The polypyrolle and polyaniline redox centres appear to be independent of one another.

We observe that the rate of electrodeposition of polypyrolle computed from a plot of oxidative peak current versus time, indicate that, the rate of electrodeposition of polypyrolle on bare carbon is nearly four times that of polypyrolle on a bentonite- aniline matrix. Compare Figures 15 and 21 . This is probably due to the fact that, the ingress of the pyrolle monomer in the montmorillonite matrix, is sterically more favored as compared to its ingress into a host matrix where aniline monomer is already resident.

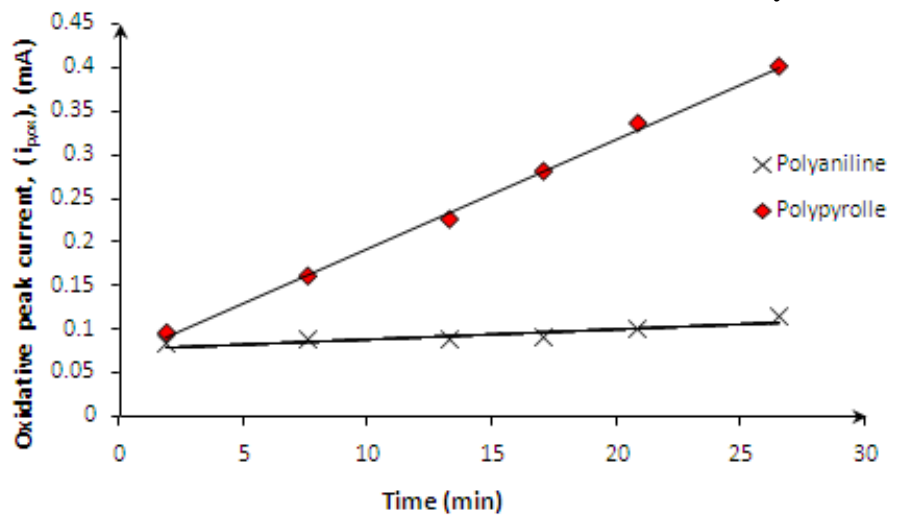

Figure 21: Plot of oxidative peak currents, (ip, and $0 x)$, $(\mathrm{mA})$ versus time $(\mathrm{min})$ for polypyrolle electrodeposited on bentonite-aniline modified electrode. $0.2 \mathrm{M}$ pyrolle and $1.5 \mathrm{M} \mathrm{H}_{2} \mathrm{SO}_{4}$. Potential range 0.3 to $0.85 \mathrm{~V}$, scan rate $20 \mathrm{mV} / \mathrm{s}$.

\section{Electrochemical Features of Physi-sorbed Aniline and Pyrolle Monomers}

$0.1 \mathrm{M}$ aniline and $0.2 \mathrm{M}$ pyrolle in $1 \mathrm{M} \mathrm{H}_{2} \mathrm{SO}_{4}$ were exposed to $0.2 \mathrm{~g}$ of bentonite. The mixture was allowed to stay undisturbed. We then added $2 \mathrm{~g}$ of pure bentonite to the mixture and the solution made up to 1.5 $\mathrm{M} \mathrm{H}_{2} \mathrm{SO}_{4}$. After exposure for 48 hours, the mixture was filtered and the bentonite slurry used to prepare electrodes. The working electrode prepared was cycled from -0.3 to $0.9 \mathrm{~V}$ at a scan rate of $20 \mathrm{mV} / \mathrm{s}$. The resultant cyclic voltammograms were broad and misshapened, (see Figure 22).

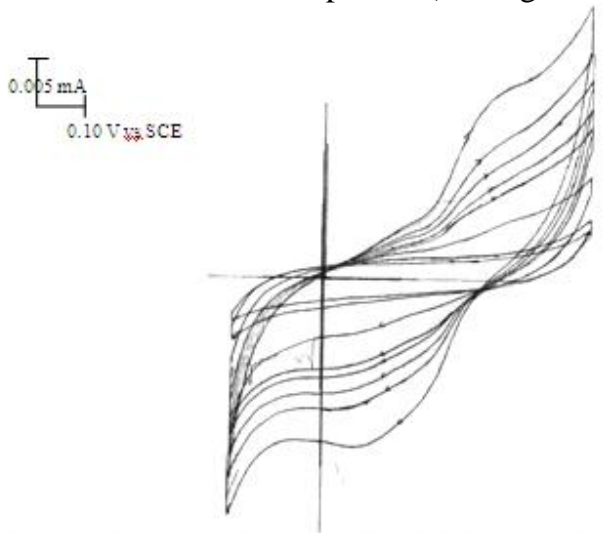

Figure 22: $\mathrm{CV}$ response of electrodeposition of physi-sorbed aniline and pyrolle monomers in solution $1.5 \mathrm{M}$ $\mathrm{H}_{2} \mathrm{SO}_{4}$. Potential range -0.3 to $0.90 \mathrm{~V}$, scan rate $20 \mathrm{mV} / \mathrm{s}$. 
A similar process was repeated but this time there was no pyrolle monomer. The $0.2 \mathrm{~g}$ of bentonite was exposed to a solution containing $0.1 \mathrm{M}$ aniline and $1 \mathrm{M} \mathrm{H}_{2} \mathrm{SO}_{4}$. Then $2 \mathrm{~g}$ of bentonite was added. The bentonite slurry obtained was then used to make the electrodes. The potential of the working electrode was then scanned from -0.3 to $0.85 \mathrm{~V}$. The resultant cyclic voltammograms were broad and misshapened, (see Figure 23).

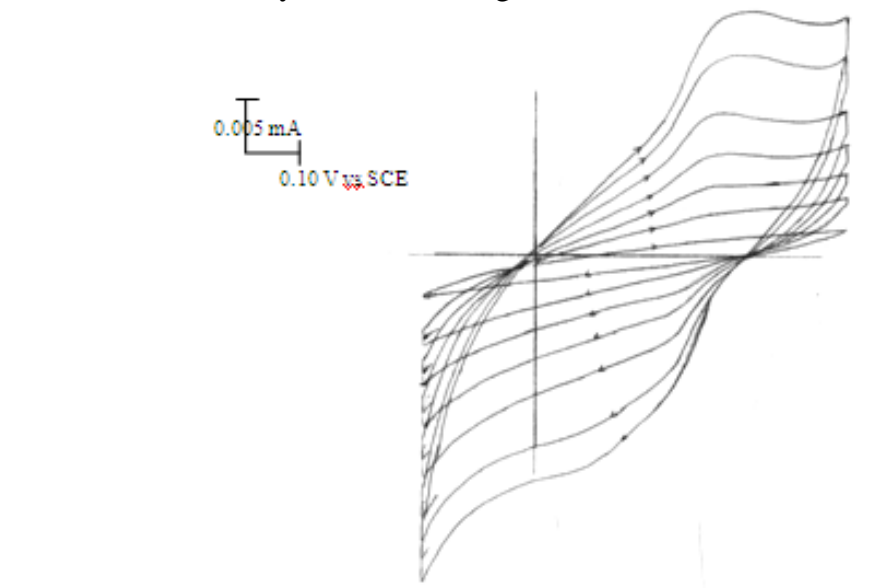

Figure 23: CV response of electrodeposition of physi-sorbed aniline monomer (no pyrolle) in solution $1.5 \mathrm{M}$ $\mathrm{H}_{2} \mathrm{SO}_{4}$. Potential range -0.3 to $0.85 \mathrm{~V}$, scan rate $20 \mathrm{mV} / \mathrm{s}$.

The oxidation and reduction peak potential were broad bands with potential in range from $0.40-0.70$ $\mathrm{V}$ for the oxidation peak potential and $0.10 \mathrm{~V}-0.30 \mathrm{~V}$ for the reduction peak potential.

\section{Pyrrole Adsorbed on Bentonite}

A solution containing $0.2 \mathrm{M}$ pyrolle and $1 \mathrm{M} \mathrm{H}_{2} \mathrm{SO}_{4}$ was allowed to stay in contact with bentonite. The pyrolle monomer was adsorbed on the bentonite. The bentonite with adsorbed pyrolle was then used to modifiy the carbon graphite working electrode. The potential of this electrode was then cycled from -0.3 to $0.89 \mathrm{~V}$ and in a solution containing $1 \mathrm{M} \mathrm{H}_{2} \mathrm{SO}_{4}$ at a scan rate of $20 \mathrm{mV} / \mathrm{s}$. The resultant cyclic voltammetric response is shown in Figure 24.

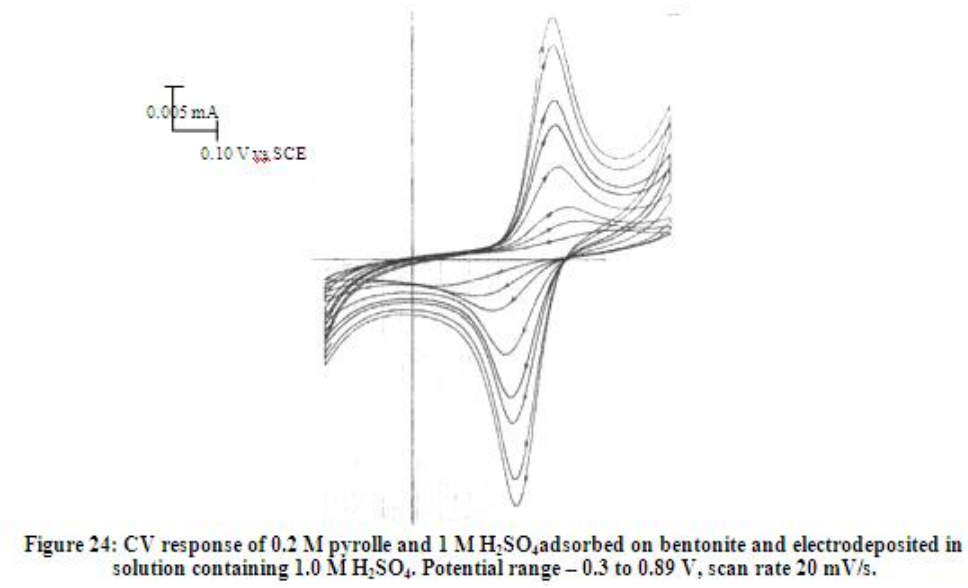

Computation of the electrodeposition rate from a plot of the oxidative peak current versus time yielded the same values as that of polypyrolle electrodeposited on a bentonite modified electrode. See Figure 25. 


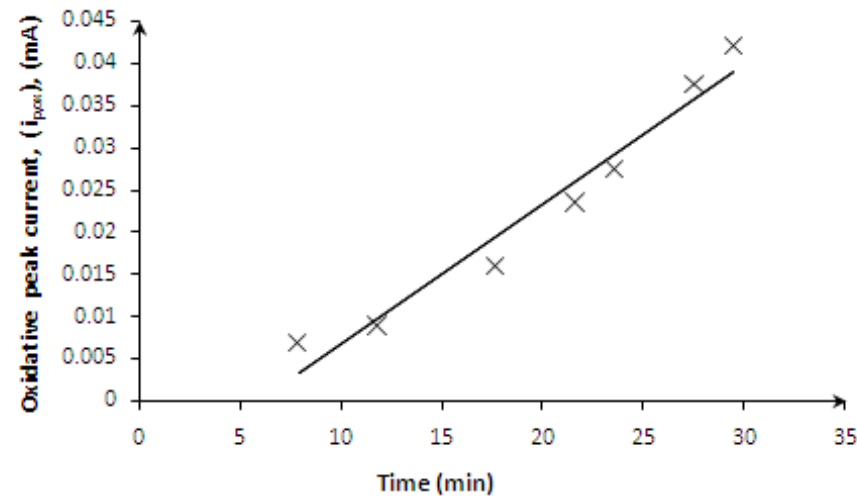

Figure 25: Plot of oxidative peak currents, (ip, and $\mathrm{ox}$ ), $(\mathrm{mA})$ versus time $(\mathrm{min})$ for $0.2 \mathrm{M}$ pyrolle and $1 \mathrm{M}$ $\mathrm{H}_{2} \mathrm{SO}_{4}$ adsorbed on bentonite and electrodeposited in solution containing $1.0 \mathrm{M} \mathrm{H}_{2} \mathrm{SO}_{4}$. Potential range -0.3 to $0.89 \mathrm{~V}$, scan rate $20 \mathrm{mV} / \mathrm{s}$.

A plot of the oxidative peak current and the reductive peak current gave the redox efficiency of the process as $97 \%$. See Figure 26.

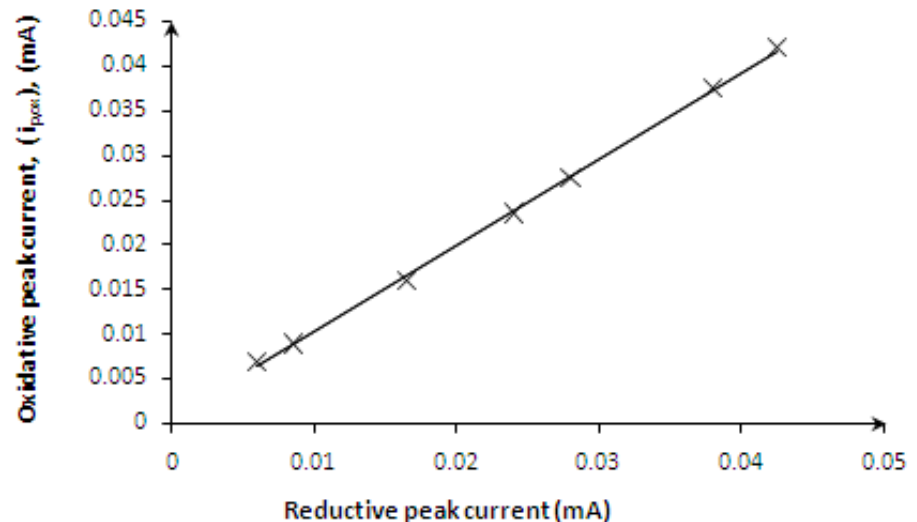

Figure 26: Plot of oxidative peak current, (ip, and ox), $(\mathrm{mA})$ versus reductive peak current $(\mathrm{mA})$ for $0.2 \mathrm{M}$ pyrolle and $1 \mathrm{M} \mathrm{H}_{2} \mathrm{SO}_{4}$ adsorbed on bentonite and electrodeposited in solution containing $1.0 \mathrm{M} \mathrm{H}_{2} \mathrm{SO}_{4}$. Potential range -0.3 to $0.89 \mathrm{~V}$, scan rate $20 \mathrm{mV} / \mathrm{s}$.

The variation of the oxidative peak current with $\left[\mathrm{H}_{2} \mathrm{SO}_{4}\right]$ is shown in the table1 below.

Table 1: The variation of the oxidative peak current with $\left[\mathrm{H}_{2} \mathrm{SO}_{4}\right]$

\begin{tabular}{|c|c|}
\hline & $\mathbf{E}_{\mathbf{p}, \mathbf{x}}(\mathbf{V})$ \\
\hline 0.494 & {$\left[\mathrm{H}_{2} \mathrm{SO}_{4}\right]$} \\
\hline 0.474 & $0.1 \mathrm{M}$ \\
\hline 0.464 & $1.0 \mathrm{M}$ \\
\hline
\end{tabular}

It is apparent that, the variation of oxidative peak potential with the electrolyte solution $\mathrm{pH}$ is not linear. The variation of oxidation potential and solution $\mathrm{pH}$ for the initial data points suggests a shift of 20 $\mathrm{mV} / \mathrm{pH}$. This value if considered in isolation suggests that, the redox process is not a $1 \mathrm{H}^{+} / 1 \mathrm{e}^{-}$process.

A plot of the oxidative peak current versus scan rate/square root of scan rate yielded a linear plot in the plot of oxidative peak current versus square root, suggesting that, the polypyrolle redox process is diffusion limited. 


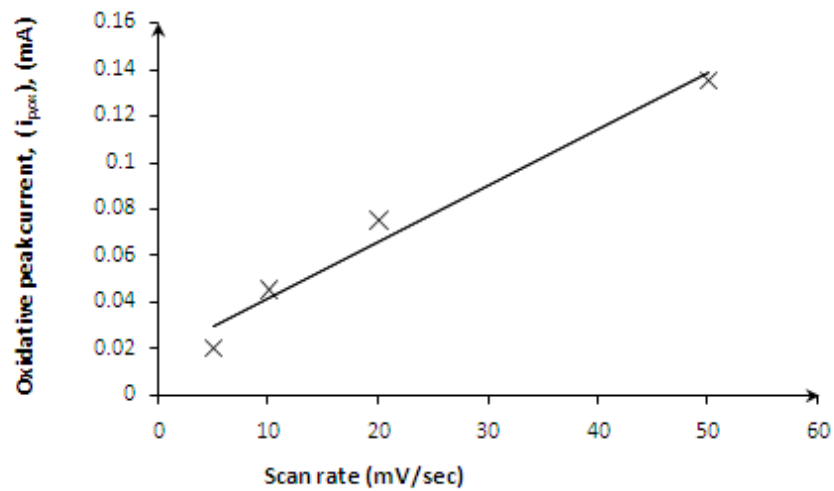

Figure 27: A plot of oxidative peak current ( $i_{\mathrm{p}, 02}$ )versus scan ratefor $0.2 \mathrm{M}$ pyrolle and $1 \mathrm{M} \mathrm{H}_{2} \mathrm{SO}_{4}$ adsorbed on bentonite and electrodeposited in solution containing $1.0 \mathrm{M} \mathrm{H}_{2} \mathrm{SO}_{4}$. Potential range -0.3 to $0.89 \mathrm{~V}$.

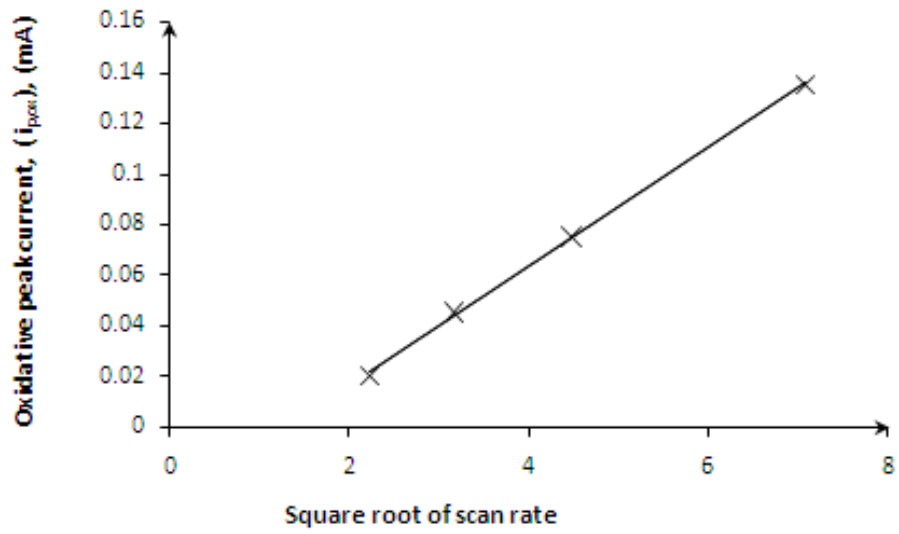

Figure 28: A plot of oxidative peak current $\left(i_{\text {por }}\right)$ versus square root of scan ratefor $0.2 \mathrm{M}$ pyrolle and $1 \mathrm{M}$ $\mathrm{H}_{2} \mathrm{SO}_{4}$ adsorbed on bentonite and electrodeposited in solution containing $1.0 \mathrm{M} \mathrm{H}_{2} \mathrm{SO}_{4}$. Potential range -0.3 to $0.89 \mathrm{~V}$.

\section{Conclusion:}

The results presented in this paper show that polypyrolle can be electrosynthesized in aqueous electrolyte media, with sulphuric acid as the supporting electrolyte. This is in contrast to the use of non-aqueous media and organic salt as supporting electrolytes.

We have also observed tremendous improvement in the polypyrolle redox process when electrosynthesized on a montmorillonite host matrix.

The reduction in the redox versatility of polypyrolle when electrodeposited on a polyaniline loaded montmorillonite, is a veil confirmation of intercalation of the polyaniline polymer in the clay montmorillonite matrix (tetrahedral and octahedral layers).

\section{References:}

[1]. Shirakawa H, Louis E.J., MacDiarmid A.G., Chiang C.K., Heeger A.J., 1977, Synthesis of electrically conducting organic polymers: halogen derivatives of polyacetylene, $(\mathrm{CH})_{x}$, J. Chem. So.c Chem. Commun., 579.

[2]. Abrissani C., Bongini A., Mastragostino M., Zanelli A., Barbarella G., Zambianchi M., 1995, Conductive electroactive polymers: intelligent polymer systems, Advanced materials, 7, 57

[3]. Diaz A.F., Lee W.J., Logan J.A., and Green D.C., 1980, Chemical modification of a polypyrrole electrode surface, J., Electroanal. Chem., 108, 377-380.

[4]. Diaz A.F., Kanazawa K.K., and Gardini G.P., 1986, Electronically conducting polymers, J.Chem Soc. Chem. Commun., 14 , 635.

[5]. Shirakawa H, Louis E.J., MacDiarmid A.G., Chiang C.K., Heeger A.J., 1977, Synthesis of electrically conducting organic polymers: halogen derivatives of polyacetylene, $(\mathrm{CH})_{x}$, J. Chem. Soc Chem. Commun., 579.

[6]. Waltman R.J., Bargon J., and Diaz A.F., 1983, Electrochemical studies of some conducting polythiophene films, J.Phys. Chem., 87, 1459-1463.

[7]. Wang H.L., Toppare L., and Fernandez J.E., 1990, Conducting polymer blends: polythiophene and polypyrrole blends with polystyrene and poly(bisphenol A carbonate), Macromolecules, 23, 1053.

[8]. Wei Y., Chan C.C., Tran J., Jang G.W., and Hsueh K.F., 1991, Electrochemical polymerization of thiophenes in the presence of bithiophene or terthiophene: kinetics and mechanism of the polymerization, Chem. Mat., 3, 888.

[9]. Alcacer L., 1987, Conducting Polymers, D. Reidel Publishing Company, 20.

[10]. Andrieux C.P., Audebert P., Haipot P., Saveant J.M., 1991, Identification of the first steps of the electrochemical polymerization of pyrroles by means of fast potential step techniques, J. Phys. Chem., 95, 10158.

[11]. Gazzoti W.A.J., Casalbore-Miceli G., Mitzakoff S., Geri A., Gallazzi M.C. and De Paoli M.A., 1999, Conductive polymer blends as electrochromic materials, Electrochim. Acta.,44(12), 1965-1971.

[12]. Gofer Y., Killian J.G., Giaccai J., Poehler T.O., Searson P.C., 1997, Phenylene-2-thienyl conducting polymers for charge storage applications,Appl. Phys.Lett., 71, 1582-1584. 
[13]. MacDiarmid A., 1990, Conductive Polymers, and Plastic Batteries, Basic Energy Sciences, 57, 58

[14]. Orata D.O., and Segor F., 1999, Bentonite (clay montmorillonite) as a template for electrosynthesis of thyroxine, Catalysis Letters, 58, 157-162.

[15]. Orata D.O., and Segor F., 2000, Electrodeposition of polyaniline on acidified clay montmorillonite modified electrode, Reactive \& Functional Polymers, 43, 305-314. 